\title{
Risk factors for breast cancer with applications to selection for the prevalence screen
}

\author{
FREDA E ALEXANDER, ${ }^{1}$ M MAUREEN ROBERTS, ${ }^{2}{ }^{3}$ AND ANNE HUGGINS ${ }^{3}$ \\ From the Medical Computing and Statistics Unit, ${ }^{1}$ University of Edinburgh; Department of Clinical Surgery, ${ }^{2}$ \\ University of Edinburgh; and Edinburgh Breast Screening Clinic ${ }^{3}$
}

SUMMARY There have been many studies of individual risk factors for breast cancer; most of the factors concerned may be broadly grouped into demographic and dietary, reproductive history, endocrine related, family history of breast cancer, and previous history of breast disease. Some of these studies have examined the combined effect of these factors. The present case-control study does this in the context of a randomised controlled trial of breast cancer screening. The relative risks that we have obtained are, in general, of similar magnitude to those in other reports. The relevance of the results to a screening programme is discussed.

In this study, data from the Edinburgh randomised trial of breast screening ${ }^{1}$ are used to address two issues: firstly, examination of risk factors for breast cancer using case-control design, and, secondly, assessment of whether these factors could be used to select women for an initial or prevalence screen and thus reduce the cost of screening.

\section{Methods}

In 1978, a screening programme was started in Edinburgh; 23000 women aged 45 to 64 were invited for screening by clinical examination and mammography. Invitations were issued over the period November 1978 to December 1981. These women are being offered annual screening. From 1982 until December 1985, women in this age group who have newly come to Edinburgh or who have recently become 45 have been invited to participate. The women invited for screening are a $50 \%$ random sample of the population in the Edinburgh randomised trial of breast screening. ${ }^{1}$ They are also part of the study population of the UK National Trial of the Early Detection of Breast Cancer. ${ }^{2}$ The present study is restricted entirely to women who have attended for routine screening after receiving an invitation; this is $64 \%$ of the women invited.

The cases are all women whose first or later routine screening visit led to the detection of cancer or who presented symptomatically within one year of screening and who were on computer file by 28
February 1984 . There are 186 cases.* The screening visit for screen-detected cases and the last screening visit before diagnosis of interval cases take the role normally assigned in case-control studies to 'date of diagnosis'. The data are all collected at that point.

For each case four $\dagger$ controls were randomly selected by computer from a control pool of all women who had attended the same routine visit within 12 months of the case, who were aged within 9 months of the case and who were healthy in the sense of having no breast abnormality diagnosed at screening and no interval presentations of breast cancer within the next 12 months. The information was obtained using the screening clinic coded forms before the woman was examined and is restricted to conventional risk factors. These are age at menarche, number of full term pregnancies, age at first full term pregnancy, last monthly period, whether a hysterectomy (for menstrual status), use and duration of use of oral contraceptive pill (and whether this was used before the first pregnancy), family history of breast cancer, previous history of benign breast disease, and marital status.

The results reported here are almost all obtained with the matching retained: a preliminary analysis using Mantel-Haenszel methods for matched sets with Miettinen estimate of relative risk (RR) was used to

"Of the cases, 98 were screen-detected at the first visit and 63 at later visits; 25 were not screen-detected.

tFor one first visit case a control was selected who was a case at a later round and so was excluded; this case has only 3 controls. 
determine which factors should be examined in the main analysis which used conditional maximum likelihood methods. ${ }^{3}$ Interactions with age in five-year groupings and with menstrual status have been investigated throughout but are reported only when they are significant. To examine interactions with menstrual status the matching was broken so as not to exclude a large amount of data.

The menstrual status is taken from the last recorded monthly period up to and including the appropriate screening visit. We defined our categories as postmenopausal (last monthly period (LMP) more than 12 months ago), peri-menopausal (LMP 6-12 months ago), and pre-menopausal (LMP $<6$ months ago). Women who had had a hysterectomy were counted separately but no data were available on whether their ovaries had been removed or why the hysterectomies had been performed.

After the preliminary analysis, we introduced an extra category. This was 'menopausal' (LMP over 8 weeks to 1 year). It is often difficult to know from the data recorded at the screening visit whether a women is indeed menopausal. So we attempted to delineate accurately from the available data those women whose menopause had in fact started; it is clearly unsatisfactory from a gynaecological point of view and will lead to misclassifications in both directions. However we found that at least in women attending screening it served as a reasonable proxy as the majority of women put into this category are postmenopausal two years later (table 1). There is also considerable evidence ${ }^{45}$ that increased cycle length is related to the onset of the menopause.

Finally, the population from which women in this study have been selected (women who have been invited and have attended screening) has been examined to obtain the population prevalence of these factors and to assess the relevance of our results to screening policy.

\section{Results}

\section{CASE-CONTROL STUDY}

The results of the preliminary analysis are shown in table 2. The factors for which the relative risk was significantly different from 1 were: age at menarche, family history of breast cancer, and past history of benign breast disease where the effect was most

Table 1 Transition matrix for time lapsed from last monthly period (LMP)

\begin{tabular}{|c|c|c|c|c|c|}
\hline & \multicolumn{5}{|c|}{ Time lapsed from LMP at 3rd screen } \\
\hline & $\underset{(0-56 \text { days })}{A}$ & $\begin{array}{l}B \\
\text { ( } 57 \text { days }-<6 \text { months) }\end{array}$ & $\begin{array}{l}C \\
(6 \text { months }-<1 \text { year })\end{array}$ & $\begin{array}{l}D \\
(1-<2 \text { years })\end{array}$ & $\begin{array}{l}E \\
(2.5 \text { years })\end{array}$ \\
\hline $\begin{array}{l}\text { Time } \\
\text { lapsed } \\
\text { at 1st } \\
\text { screen }\end{array}$ & $\begin{array}{cc}\text { A } & 1529 \\
\text { B } & 47 \\
\text { C } & 2 \\
\text { D } & 3\end{array}$ & $\begin{array}{r}297 \\
37 \\
4 \\
5\end{array}$ & $\begin{array}{r}204 \\
46 \\
9 \\
4\end{array}$ & $\begin{array}{r}277 \\
126 \\
55 \\
21\end{array}$ & $\begin{array}{l}102 \\
196 \\
284 \\
540\end{array}$ \\
\hline
\end{tabular}

Includes all women in the initial cohort of the Edinburgh Screening Programme who have attended their first three routine screenings in the appropriate year (so that the time gap from 1 st to 3 rd is normally 2 years and cannot be more than 3 years) and who reported a menstrual period within the last two years at the first screen (and who have never reported a hysterectomy).

Table 2 Crude relative risks-dichotomous exposure factors

\begin{tabular}{|c|c|c|c|c|c|c|}
\hline Factor & Age range (years) & Excluded categories & $\%$ Cases & $\%$ Controls $\ddagger$ & $R R^{*}$ & $95 \% \mathrm{Clt}$ \\
\hline $\begin{array}{l}\text { Married: Never } v \text { Ever } \\
\text { Menarche: }<15 v \geqslant 15 \text { yr } \\
\text { Parous } v \text { Nulliparous } \\
\text { No pregnancies }>4 v \leqslant 4 \\
\text { No preg before } 30 v \text { FFTP }<30 \\
\text { FFTP } \geqslant 30 v \text { FFTP }<30 \\
\text { OC pill: Ever } v \text { Never } \\
\text { OC pill: Used } \geqslant 1 \text { yr } v<1 \text { yr } \\
\text { Mother a case: Yes } v \text { No } \\
\text { Sister a case: Yes } v \text { No } \\
\text { Past breast excision: Yes } v \text { No } \\
\text { Past breast cyst: Yes } v \text { No } \\
\text { Past breast problems: Yes } v \\
\text { Age at (natural menopause } \\
\text { Premenopausal } v \text { Postmenopausal }\end{array}$ & $\begin{array}{l}\text { All } \\
\text { All } \\
\text { All } \\
\text { All } \\
\text { All } \\
\text { All } \\
45-54 \\
45-54 \\
\text { All } \\
\text { All } \\
\text { All } \\
\text { All } \\
\text { All } \\
\\
55-56 \\
(45-54) \\
(45-49) \\
(50-54)\end{array}$ & $\begin{array}{l}- \\
- \\
\bar{N} \text { ulliparous } \\
\overline{\text { Nulliparous }} \\
\overline{\text { Never - users }} \\
- \\
- \\
- \\
- \\
\text { Women with previous } \\
\text { hysterectomy } \\
\text { LMP } 6 \text { mth-1 yr } \\
\text { Artificial menopause }\end{array}$ & $\begin{array}{r}10 \cdot 7 \\
83 \cdot 9 \\
78 \cdot 5 \\
5 \cdot 5 \\
40 \cdot 9 \\
24 \cdot 7 \\
31 \cdot 8 \\
11 \cdot 1 \\
4 \cdot 3 \\
6 \cdot 5 \\
8 \cdot 1 \\
2 \cdot 7 \\
23 \cdot 1 \\
\\
44 \cdot 2 \\
63 \cdot 2 \\
73 \cdot 3 \\
53 \cdot 3\end{array}$ & $\begin{array}{r}8.5 \\
76 \cdot 4 \\
80 \cdot 2 \\
8 \cdot 7 \\
34 \cdot 2 \\
18 \cdot 0 \\
29 \cdot 7 \\
35 \cdot 0 \\
5 \cdot 0 \\
2 \cdot 2 \\
5 \cdot 9 \\
1 \cdot 3 \\
16 \cdot 0 \\
\\
45 \cdot 4 \\
57 \cdot 2 \\
84 \cdot 4 \\
35 \cdot 0\end{array}$ & $\begin{array}{l}1 \cdot 22 \\
1.64 \\
0.90 \\
0 \cdot 60 \\
1 \cdot 34 \\
1.58 \\
1 \cdot 14 \\
4.83 \\
0.86 \\
3 \cdot 15 \\
1.39 \\
2 \cdot 11 \\
1.61 \\
\\
1 \cdot 10 \\
1.35 \\
0.31 \\
2.94\end{array}$ & $\begin{array}{l}0.89-1.67 \\
1.14-2.33 \\
0.74-1.09 \\
0.29-1.23 \\
1.03-1.74 \\
1.07-2.32 \\
0.75-1.73 \\
1.97-11.87 \\
0.37-2.01 \\
1.33-7.46 \\
0.72-2.68 \\
0.63-7.05 \\
1.10-2.36 \\
\\
0.78-1.56 \\
0.88-2.08 \\
0.14-0.70 \\
1.82-4.76\end{array}$ \\
\hline
\end{tabular}

- Relative risk: Mantel-Haenszel estimate of odds ratio; $\uparrow 95 \%$ Confidence intervals: approximate formula (Miettenen) $\ddagger$ percentages quoted are those positive and are based on all cases, all controls (ignoring matching). §First full term pregnancy. 
Table 3 Menstrual status categories of women aged 45-54 in present study

\begin{tabular}{|c|c|c|c|c|c|c|c|}
\hline \multirow[b]{2}{*}{ Time (LMP) } & \multicolumn{2}{|l|}{ Pre menopausal } & \multirow{2}{*}{ 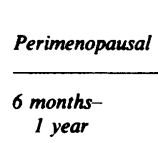 } & \multicolumn{2}{|c|}{ Postmenopausal } & \multirow{2}{*}{$\begin{array}{l}\text { Artificial } \\
\text { menopause }\end{array}$} & \multirow[b]{2}{*}{ Total } \\
\hline & $\begin{array}{l}0-56 \\
\text { days }\end{array}$ & $\begin{array}{l}57 \text { days- } \\
<6 \text { months }\end{array}$ & & $1-5$ year & $>5$ years & & \\
\hline \multicolumn{8}{|l|}{ lst defn } \\
\hline Cases & 31 & 12 & 5 & 20 & 7 & 10 & 85 \\
\hline Controls & 142 & 22 & 7 & 89 & 38 & 40 & 338 \\
\hline 2nd defn & Premenopausal & \multicolumn{2}{|c|}{ Menopausal } & \multicolumn{2}{|c|}{ Postmenopausal } & $\begin{array}{l}\text { Artificial } \\
\text { menopause }\end{array}$ & \\
\hline
\end{tabular}

The relative risk for menopausal compared with pre- and post-menopausal for this age group is $2 \cdot 71$, with an approximate $95 \%$ confidence interval of $1 \cdot 39$ to $5 \cdot 28$.

noticeable for past cysts but the numbers were very small. The absence of a pregnancy before 30 just attained statistical significance.

No evidence of relation to risk was found for marital status, use of oral contraceptives (ever-users compared to never-users), age at natural menopause or hysterectomy. Among ever-users of the oral contraceptive pill those who had used the pill for more than one year were at significantly higher risk. This, however, cannot be interpreted as a dose-response relation since those women who had used the pill for less than one year were at lower risk than non-users. Therefore the relation is unlikely to be causal.

Menstrual status (pre-menopausal as opposed to post-menopausal with the peri-menopausal group excluded) in the age group 45-54 as a whole yielded a RR very close to 1 . In this case, however, there was highly significant interaction with age; the younger (45-49) women were apparently at decreased risk while pre-menopausal and older (50-54) women were at increased risk. After noting that within these two age groups there were five peri-menopausal cases and only seven peri-menopausal controls, it seemed possible that the pre-menopausal categories in the two age groups contain different proportions of women whose menopause has begun. These considerations led to the definition of our additional category "menopausal". The numbers of cases and controls in each category are shown in table 3.

In the multivariate analysis we restricted attention to age at menarche, age at first full term pregnancy, breast cancer reported in a sister, past benign breast disease, menstrual status, and age at menopause, which we included because the dichotomous approach might not have permitted us to detect an effect which is commonly reported.

The results are shown in tables 4 and 5 . Each of the factors age at menarche, breast cancer reported in a sister, past benign breast disease, and menopausal versus other menstrual status made a significant improvement to the multivariate model. Age at first full term pregnancy once again just attained formal

Table 4 Multivariate analysis

\begin{tabular}{|c|c|c|c|c|}
\hline Factor & (Level) & Score* & $p \dagger$ & Adjusted RR $\mathbf{R}$ \\
\hline Past breast history & $\begin{array}{l}\text { None } \\
\text { Some } \\
\text { Trend\$ }\end{array}$ & $\begin{array}{l}- \\
6.79 \\
9.63\end{array}$ & $\begin{array}{l}- \\
<0.01 \\
<0.01\end{array}$ & $\begin{array}{c}1.00 \\
1.41 \\
1.38 / \text { unit }\end{array}$ \\
\hline Sister a case & $\begin{array}{l}\text { No } \\
\text { Yes }\end{array}$ & 9.92 & $<0.01$ & $\begin{array}{l}1.00 \\
3.42\end{array}$ \\
\hline Menopausal & No & $\frac{5 \cdot 92}{11 \cdot 51}$ & - & $\begin{array}{l}3.42 \\
1.00 \\
2.98\end{array}$ \\
\hline Age at first full term pregnancy** & $\begin{array}{l}<25 \\
25-29\end{array}$ & - & - & $\begin{array}{l}1.00 \\
1.23\end{array}$ \\
\hline Age at menarche & $\begin{array}{l}\text { not }<30 \\
>=15 \\
<15\end{array}$ & $\frac{4 \cdot 11}{8 \cdot 00}$ & $\begin{array}{l}<0.5 \\
- \\
<0.01\end{array}$ & $\begin{array}{l}1.53 \\
1.00 \\
1.90\end{array}$ \\
\hline
\end{tabular}

- Score statistic for addition of the current factor to the model containing the others.

+ p-values are based on the asymptomatic chi-square distribution for the score.

$\ddagger$ RRs are adjusted for all other factors appearing in the table.

$\S$ Linear trend across levels $0,1,2$, where " 0 " represents none, " 1 " represents only one breast examined at a hospital diagnostic clinic, and " 2 " represents more than that

The model with a separate parameter for each menstrual status failed to converge.

** Statistics are given for a model of linear trend across the categories.

Table 5 Effect of age of natural menopause in postmenopausal women aged 55-56

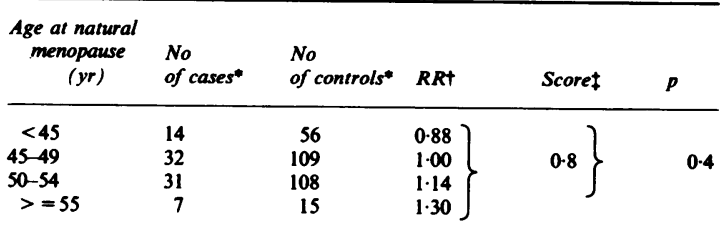

- Numbers of cases and controls in the data available for analysis using the matched design; there were 45 sets with 4 controls, 31 sets with 3 controls, 7 sets with 2 controls, and 1 set with 1 control.

+ RR obtained from the model with linear trend across the 4 age-at-menopause categories; estimated increase in risk/level $=1 \cdot 14(95 \% \mathrm{CI}=0 \cdot 18-7 \cdot 14)$

¥ Score for ldf trend model; alone or added after the full multivariate model made little difference. 
statistical significance. We also examined menarche in three age categories $(<12,12-14\rangle$,15 years $)$ and found no significant difference between the first two categories. Our evidence is therefore that a late menarche is protective rather than an earlier one being a risk factor. We still found no evidence for change in risk associated with age at menopause in postmenopausal women in our age range (table 5).

None of the factors we have found significant showed any significant interactions with age apart from menstrual status, which we have already discussed; we were confident that (with the possible exception of late pregnancy/nulliparity) there was no evidence of interaction with screening round.

\section{APPLICATION TO THE PREVALENCE SCREEN}

Table 6 gives the population prevalence of each of the factors which have been found to be significant in the multivariate model, and also of symptoms which were first reported at the initial routine screen. The prevalence in the first year cancer cases is low for each factor apart from menarche.

We then used a combination of these factors to find whether they could be used in this way to select a "high-risk" population to be screened. The results are shown in table 7.

Finally, in table 8 the same factors are assessed as a possible adjunct to clinical modality screening*; here we postulated an imaginary situation in which all women who come from screening have a clinical examination and interview; mammography is then performed only on those with a clinical abnormality and/or in a high-risk group defined as before. The percentages of cancers which would have been detected and of healthy women who would have received mammography are shown.

\section{Discussion}

The sample of cases of breast cancer that we have used here has been drawn from a cohort of women

*In the Edinburgh clinic each modality reports independently. At the prevalence screen the mammographic modality itself detected virtually all the cases that were detected (96\%) and the clinical modality detected $69 \%$.

Table 6 Prevalence of risk factors, signs, and symptoms

\begin{tabular}{lllc}
\hline & Level & $\begin{array}{c}\text { \% Prevalence } \\
\text { in population }\end{array}$ & $\begin{array}{c}\text { \% Prevalence in 1st } \\
\text { year cancer cases }\end{array}$ \\
\hline Symptoms reported & Lump/Pain & 1.0 & 13.5 \\
Previous history & Cyst/Excision & 6.9 & 8.6 \\
Previous history & Any & 15.0 & 21.0 \\
Family history & Sister a case & 2.7 & 5.6 \\
Menstrual status & Menopausal & 6.7 & 9.9 \\
First full term & & & \\
pregnancy & Not before 30 & 35.5 & 41.6 \\
Menarche & $<15$ & 76.7 & 85.4 \\
\hline
\end{tabular}

Table 7 Percentage of cancers and healthy women in a high risk group defined by combined criteria

\begin{tabular}{llc}
\hline Factors & $\begin{array}{l}\text { \% of healthy } \\
\text { women }\end{array}$ & $\%$ lst round cancers \\
\hline BMD & 6.9 & 8.6 \\
BMD or FH & 12.8 & 19.8 \\
BMD or FH or M & 19.2 & 29.6 \\
BMD or FH or M or FFTP & 47.7 & 55.6 \\
\hline
\end{tabular}

Key for tables 7 and 8

BMD A past breast cyst/excision

FH History of breast cancer in mother/sister

M Menopausal

FFTP No full term pregnancy before age 30

CM Clinical modality detected an abnormality

Of the factors in the multivariate model these factors have been chosen because they could be used in practice by a woman herself to elect for screening; a mother has been included in the family history because it is possible that our results are really positive for first degree family history and are by chance concentrated in the sisters.

To include the presence of symptoms as a criterion for selection could raise practical problems and is not necessarily described accurately by our data; however, if we had included them, then line 3 of the table would give $20 \%$ of healthy women and $40 \%$ of cancers.

attending annual breast screening examinations; the controls have been derived from the same cohort, matched for age and screening round so that our method should yield unbiased estimates of the "risk" of a breast cancer diagnosis in such a population of screened women. Thus our study design is particularly appropriate for discussing strategies for screening at the beginning of a screening programme.

Our first interest was, however, aetiological factors. Here the strengths of our design are that we have population controls, very tightly matched on age, and that our data are prospective. The design of casecontrol studies carried out using women from screening cohorts has been discussed in detail by Dubin et al. ${ }^{7}$ They recommend adjustment in the analysis for 'symptomaticity', year of first screen, and screening round. The women in the present study are all asymptomatic in the sense that no symptoms led

Table 8 Possible use of risk factors as adjunct to the clinical modality at initial screening

\begin{tabular}{cll}
\hline Criteria & $\begin{array}{l}\text { \% cancers } \\
\text { detected }\end{array}$ & $\begin{array}{l}\text { \% healthy given } \\
\text { mammography }\end{array}$ \\
\hline CM & 69.1 & 5.11 \\
CM or BMD & 72.8 & 11.1 \\
CM or BMD or FH & 77.8 & 16.5 \\
CM or BMD or FH or M & 81.5 & 25.2 \\
CM or BMD or FH or M or FFTP & 86.4 & 51.7 \\
\hline
\end{tabular}


them to seek medical advice before they received an invitation to screening. Our method of matching has controlled for screening round and year of first screen as well as for age, which is the most important potential confounding factor. We should have preferred to adjust for social class, height, and weight but the information was available for only $10 \%$ of the women.

A further source of bias (length biased sampling ${ }^{8}$ ) arises if our sample of cases cannot be regarded as a random sample of cases which would arise naturally in the screened population. We have tried to avoid this by including all interval cases, but since we had such a large proportion of prevalent cases which have pathological characteristics consistent with slower growth, 9 our cases are still somewhat biased towards those with longer detectable preclinical stage. This could bias our relative risk estimates for any factors which are independently related to the length of that stage. We can find no evidence that this is the case for any of the factors we have been considering apart possibly from late first pregnancy and nulliparity. ${ }^{10}$ We did nevertheless confirm that our results for each of the categories first screen, later screens, and interval cases are in the same direction as the overall results.

Thus the benefit associated with late age at menarche and the risks associated with family history and past breast problems may reflect genuine aetiological effects. They are consistent with the previous Edinburgh study of risk factors ${ }^{11}$ and with much of the literature. ${ }^{12}{ }^{13}$ It is particularly interesting that we have confirmed the effect of all kinds of past breast history which was reported in a previous study ${ }^{14}$ where both cases and controls have the same level of breast awareness. It is also interesting that we have found these factors to be of independent significance in a multivariate model. This model was multiplicative for relative risks and so does qualitatively confirm the interaction between family history and past benign breast disease reported recently by Page $e t$ al $^{15}$ even though our definition of benign breast disease is much broader than theirs.

We have been unable to confirm that older age at natural menopause is associated with increased risk in post-menopausal women though this is reported (eg ref 16). Our study is, however, restricted to women aged $<65$, and most reports of the effect of an older age at menopause have found it to be concentrated in older women. We have also found evidence for an increased "risk" at the time of onset of the menopause which is independent of the other factors; the whole question of the relation between "risk" and age at menopause and menstrual status is very complex, and the literature is obscured by ambiguous and inconsistent definitions of menstrual status. We have discussed this in some detail elsewhere. ${ }^{17}$
We were surprised to find that in this study parity had virtually no association with disease and that age at first full term pregnancy was of rather marginal significance. Since most studies have found nulliparous women and those who are older at their first delivery to be at increased risk, ${ }^{18}{ }^{19}$ we suspect the effect of length bias. On the other hand, the previous Edinburgh study gives similar reports and so the lack of importance of this factor may reflect a genuine difference in these women. It is interesting that Miller et $a{ }^{20}$ have found evidence that of these factors it is late age at first full term pregnancy rather than nulliparity that is critical.

The question has often been asked, and is perhaps still of interest, whether it is possible to select a subgroup of the population who are at high risk and limit a screening programme to them; a suitable aim could be to detect $80 \%$ of the available cancers by screening $20-30 \%$ of the population. ${ }^{21} 22$ For such a policy to be viable requires a factor or combination of factors which is strongly related to the disease and at the same time has low prevalence in the population. The size of relative risks found for breast cancer is not sufficiently large, and previous studies have reported negative conclusions (eg, the previous Edinburgh study, ${ }^{10}$ the HIP study, ${ }^{23}$ and one which used biochemical measures as well as epidemiological risk factors. ${ }^{21}$ A recent study from the Canadian trial ${ }^{24}$ is more optimistic but is difficult to interpret since it is based on volunteers with high rates of recent breast symptoms. Our results are the first from an actual screening programme in the UK to confirm the HIP finding that this strategy could not succeed; table 7 shows that by screening $20 \%$ of the population we could detect no more than $30 \%$ of the first round cancers (this could be increased to $40 \%$ if breast symptoms were also taken as an indication for screening). Since we have found no evidence of interaction of risk with age (except for menstrual status), our results show that a strategy of this type is equally unlikely to be successful if aimed at, for example, women under 50.

However, the dichotomy "to screen" or "not to screen" seems unnecessarily crude. It has been shown that allocating the "amount" of intervention according to risk status is preferable to uniform allocation in general, ${ }^{25}$ and in different contexts, such as ischaemic heart disease and prenatal care, the WHO has supported this even if the method of risk allocation is still crude. ${ }^{26} 27$ In our context this would mean differential allocation of screening modalities or schedules.

Our present screening programme provides clinical examination every year and mammography every two years for all women. We can consider a variety of modifications to this but two will suffice. 
Since current opinion favours mammography ${ }^{28}$ a sensible policy of differential allocation would be to screen all women of the appropriate age once by mammography and, as a result of this first examination and information on risk factors collected, then decide on the interval to the next screen for each woman. The data that we have been analysing here are not particularly appropriate for this question (all first round cases would be irrelevant), but the size of relative risks that we have encountered make us hopeful that this stragey will be viable and we are currently analysing later data. ${ }^{29}$

Another theoretical strategy could be the provision of an annual clinical examination with selective mammography for those selected by the clinical examiner or because of their risk status. This might not be ideal but in the event of mammographic facilities being unavailable it could be a practical policy in some areas. Table 8 shows how such a strategy would have performed in Edinburgh. We would have detected nearly $90 \%$ of the first round cancers by using approximately $50 \%$ of the mammographic resources. A trial is currently in progress in Canada to examine the relative effects of screening by clinical examination and mammography on breast cancer mortality, ${ }^{30}$ and their results will be relevant in this context.

The Edinburgh Breast Screening Project is funded by the Scottish Home and Health Department and the Cancer Research Campaign. We are very grateful to the members of the Project Committee for their consistent help and encouragement. We particularly wish to thank the other members of the project team for their assistance: Professor Sir APM Forrest, Dr TJ Anderson, Mr U Chetty, Dr AE Kirkpatrick, Dr J Lamb, Mr W Lutz, and Dr BB Muir.

Address for correspondence: Freda E. Alexander, Medical Computing and Statistics Unit, Edinburgh University Medical School, Teviot Place, Edinburgh EH8 9AG.

\section{References}

${ }^{1}$ Roberts MM, Alexander FE, et al. The Edinburgh randomised trial of screening for breast cancer: Description of method. Br J Cancer 1984, 50: 1-6.

${ }^{2}$ UK Breast Cancer Detection Working Group. Trial of early detection of breast cancer: Description of method. Br J Cancer 1981; 44: 618.

${ }^{3}$ Breslow NE, Day NE. Statistical methods in cancer research, 1980; Volume 1 The Analysis of Case-Control Studies, IARC scientific publications No. 32. Lyons.
${ }^{4}$ Metcalf MG, Donald RA, et al. The menopausal transition. Clin Endocr 1981; 14: 245-55.

${ }^{5}$ Wallace RB, Sherman NM, et al. Menstrual cycle patterns and breast cancer risk factors. Cancer Res, 1987; 38: $4021-4$.

${ }^{6}$ Dubin N, Pasternack BS. Breast cancer screening data in case control studies. Am J Epid, 1984; 120: 8-16.

${ }^{7}$ Dubin N, Pasternack BS. SIAM-SIMS Conference Series No. 9. 1982; 154-172.

${ }^{8}$ Simon R. Length biased sampling in etiologic studies. Am J Epid 1980; 111: 44-53.

${ }^{9}$ Anderson TJ, et al. Comparative pathology of prevalent and incident cancers detected by breast screening. The Lancet 1986; 519-23.

${ }^{10}$ Dubin N, Hutter RVP, et al. Epidemiology of minimal breast cancer among women screened in New York City. JNCI 1984; 73: 1273-9.

$"$ Duffy SW, Roberts MM et al. Risk factors for breast cancer: Relevance to screening. J Epid Comm Health $1984 ; 37,127-31$.

12 Kalache A. Risk factors for breast cancer: a tabular summary of the epidemiological literature. $B r J$ Surg 1981; 68: 797-9.

${ }^{13}$ Moore DW, et al. Breast carcinoma etiological factors. Adv Cancer Res 1983; 40: 189-253.

${ }^{14}$ Roberts MM, Jones V, et al. Risk of breast cancer in women with history of benign disease of the breast. $\mathrm{Br}$ Med J 1984; 288: 275-8.

${ }^{15}$ Dupont WD, Page DL. Risk factors for breast cancer in women with proliferative breast disease. New Engl J Med 1985; 312: 146-51.

16 Trichopoulos D, MacMahon B, et al. Menopause and breast cancer risk, JNCI 1972; 48: 605-13.

17 Alexander FE, Roberts MM. The menopause and breast cancer, $J$ Epid Comm Health 1987; 41: 94-100

18 MacMahon B, Cole P, et al. Age at first birth and breas cancer risk. Bull WHO 1970; 43: 209-21.

${ }^{19}$ Helmrich J, Shapiro S, et al. Risk factors for breast cancer. Am J Epid 1983; 117: 35-45.

${ }^{20}$ Miller AB, et al. A study of cancer, parity and age at first pregnancy, J Chron Dis 1980; 33: 595-605.

${ }^{21}$ Farewell VT. The combined effect of breast cancer risk factors. Cancer, 1977; 40: 931-6.

22 Cole $\mathrm{P}$, Morrison AS. Basic issues in population screening for cancer. JNCI 1980; 64: 1263-72.

${ }^{23}$ Shapiro S, Goldberg J. et al. Risk factors for breast cancer, A prospective study, in host environment interactions in the etiology of cancer in man. Proc. of meeting in Princeton (1972). Eds Doll and Vodojya, Lyons (1973) 169-182.

24 Schecter MT, et al Selection of women at high risk of breast cancer for initial screening. J Chron Dis 1986; 39: 253-60.

25 Alberman ED, Goldstein $H$. The 'At risk' register: A statistical evaluation. Br J Prev Med 1970; 24: 129-35.

${ }^{26}$ WHO. Methodology of multi factor preventive trials in ischaemic heart disease. Report of a Working Group, Rome, 1970, Euro. 5011 (3), Copenhagen 1973.

27 WHO. Risk approach for maternal and child health care, offset publication No. 39, Geneva 1978.

28 Roebuck EJ. Mammography and screening for breast cancer. Br Med J 1986; 292: 233-6.

29 The Edinburgh Breast Screening Project, Risk factors and the allocation of schedules for breast cancer screening, in preparation.

${ }^{30}$ Miller AB, et al. The national study of breast cancer screening. Protocol for a Canadian randomised controlled trial of screening for breast cancer in women. Clin Invest Med 1981; 4: (3-4), 227-58. 